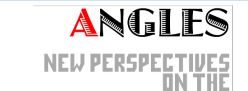

ANELOPHONE WORLD

\section{Angles}

New Perspectives on the Anglophone World

$4 \mid 2017$

Unstable States, Mutable Conditions

\title{
A Relative Clause Whose Antecedent Is Determined by the Indefinite Article: Observations on determination, qualification and stabilization of occurrences
}

Stéphane Gresset and Catherine Mazodier

\section{OpenEdition}

\section{Journals}

Electronic version

URL: https://journals.openedition.org/angles/1363

DOI: 10.4000/angles. 1363

ISSN: 2274-2042

Publisher

Société des Anglicistes de l'Enseignement Supérieur

Electronic reference

Stéphane Gresset and Catherine Mazodier, "A Relative Clause Whose Antecedent Is Determined by the Indefinite Article: Observations on determination, qualification and stabilization of occurrences",

Angles [Online], 4 | 2017, Online since 01 April 2017, connection on 06 June 2022. URL: http:// journals.openedition.org/angles/1363; DOI: https://doi.org/10.4000/angles.1363

This text was automatically generated on 6 June 2022 .

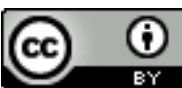

Angles est mise à disposition selon les termes de la Licence Creative Commons Attribution 4.0 International. 


\title{
A Relative Clause Whose Antecedent Is Determined by the Indefinite Article: Observations on determination, qualification and stabilization of occurrences
}

\author{
Stéphane Gresset and Catherine Mazodier
}

In memoriam Claude Charreyre

1 The purpose of this paper is to fine-tune the parameters allowing for the classification of undetached relative clauses for which the antecedent is determined by the indefinite article $\mathrm{A}$, such as:

(1) To mark the occasion, the Rome publisher Pieraldo has published a book which includes three series of portraits, and texts by, among others, Irene Bignardi and Mauro Bolognini. (BNC: EBU The Art Newspaper)

The history of these colours reads more like a romance than a sober story. (Salter 162-3)

2 In most descriptions of relative clauses, the divide between restrictive clauses (also called determinative or defining) and appositive clauses (also called non-restrictive or non-defining) is exemplified by using sentences in which the antecedent of the relative is determined by THE:

(2) She is able to read the excruciatingly small type of the book which is resting in her lap. (COCA: Laurie R. King, Leslie S. Klinger A Study in Sherlock, 2011)

(3) Callahan nodded absently without looking up from the book, which he was turning over and over in his hands. (COCA: Stephen King, Song of Susannah, 2005)

3 Here the traditional justification for treating the relative clause as restrictive/ determinative is as follows: the qualification conveyed through the relative clause in (2) constitutes the condition for the definite determination in THE. But when definite determination is justified elsewhere in the context, the relative clause merely adds qualification that is not in itself relevant to the definite determination, and is therefore 
classified as appositive, as in (3). In this case the relative clause is traditionally detached.

4 However, the case of undetached relative clauses whose antecedents are determined by A is much less clear, and in the few occasions when studied as such (Fuchs and Milner; Kleiber 1984 and 1987; Loock 2013; Malan; Rivière), it is treated in the literature as problematic and unclassifiable:

Pseudo determinative clauses have the syntax of a determinative clause but their function is similar to that of an appositive clause. (Malan 7) ${ }^{1}$

Relative clauses with an indefinite antecedent are problematic, and strangely enough are never mentioned in grammar books. [...] Relative clauses with an indefinite antecedent are therefore to be seen as so-called 'unclassifiable' relative clauses, for which new categories must be created beyond the descriptive vs. appositive classification. (Loock 2013: 31)

The interpretation of a relative clause is difficult with an indefinite NP, whatever the complexity. (Rivière and Rivière 22)

5 Our main question is therefore: why is this case problematic vis-à-vis the traditional distinction between determinative and appositive clauses? Our central hypothesis is that the instability regarding the classification of these relative clauses is to be linked to the nature of the indeterminacy of the determiner A itself.

\section{0 . Preliminary remarks on determination and stabilization}

Operations of determination will be examined within the theoretical framework of Antoine Culioli's theory of enunciative operations, in which questions of qualification and determination are apprehended in terms of the construction and delimitation of occurrences, and where the assigning of referential values is provided via the operation of location (repérage, in French). Determination therefore proceeds from the indeterminacy of a notion to the gradual determinacy of occurrences of the said notion. In this framework, notions, i.e. mental representations, have a degree of stability but are not rigidly set (they are deformable). They are apprehended through occurrences, and the question of the delimitation of occurrences is central: it is the process by which the "unfragmented solid whole" of the notion is "broken down into units":

notions have a status of predicable entities and could be described as unfragmented solid wholes; but they are apprehended through occurrences, i.e. distinguished through separate events, broken down into units (actually localized in the physical world, or imaginary) with variable properties. Through a process of abstraction, we thus pass from phenomenal occurrences to abstract occurrences. (Culioli: 69-70, original quotation in English)

7 This process involves two ways of circumscribing occurrences, quantitative and qualitative delimitation:

- quantitative delimitation involves the circumscription of the occurrence in space and/or time, it is therefore closely related to the construction of its existence in a situation;

- qualitative delimitation involves sorting the properties of the occurrence. The term "qualitative" is used at different levels; it may be used for classifying properties ("books are more interesting than magazines"), and/or differential properties ("this book was interesting"). 

French). Extraction is the primary operation by which an occurrence of a notion is circumscribed; it involves the positing of the existence of an occurrence relative to its location in time and space; in this case, quantitative (i.e. existential) delimitation of the occurrence is privileged over qualitative delimitation ("there is a book on the table"). In the case of pinpointing, it is the qualitative, differential value which is privileged in order to circumscribe the occurrence ("the book over there is interesting"). Within the class of determiners, A is typically a marker of extraction, and THE typically a marker of pinpointing.

10 As regards our analysis of relative clauses, it would seem that part of the problem stems from the possible ambiguity of the term "determination"-and therefore "determinative" - which is used in at least two different ways. Determination can, on the one hand, be seen as the linguistic operation whose trace is the determiner, different determiners thus being markers for different operations of determination. On the other hand, determination is also used to refer to the reduction of indeterminacy, from a notion to an occurrence of the notion: in this sense, one might say that $\mathrm{A}+\mathrm{N}$ is more determined than $\varnothing+\mathrm{N}$, but less determined than THE $+\mathrm{N}$.

11 These two uses of "determination" are linked: the determiner, as trace of an operation, provides clues as to how an occurrence is constructed and assigned referential values. It therefore points to the modalities of the reduction of indeterminacy. But the determiner is not the only type of marker that comes into play when assigning referential values to an occurrence: qualification of the noun via adjectives or relative clauses also contributes to the reduction of indeterminacy, and is part of the determination of the occurrence, in the second sense of reduction of indeterminacy.

It may be interesting to point out that the two uses of the term "determination" are inseparable when the determiner is the trace of a pinpointing operation. Pinpointing indicates that the occurrence of the notion is identifiable without ambiguity, by pointing to its differential properties. When an occurrence is totally circumscribed by the properties that differentiate it from other occurrences of the same class (determination in the first sense: operation conveyed by the determiner), indeterminacy is eliminated (determination in the second sense: reduction of indeterminacy). The question of the elimination of indeterminacy is therefore constitutive of the operation of pinpointing itself. In the case of determinative relative clauses with an antecedent whose determiner is THE, it is the relative clause that conveys the differential property that fully circumscribes the occurrence and allows for the pinpointing operation (as in example (2) above). The relative clause is determinative in both senses of the term: as a condition for the operation marked by the determiner (sense 1), it eliminates the indeterminacy of the occurrence (sense 2).

But in the case of extraction, as marked by the determiner A, the indeterminacy of the occurrence is not fully eliminated, the occurrence is not fully identifiable and its referential values not fully stabilized. Extraction constitutes a first step in circumscribing an occurrence by providing it with existential conditions. However, the occurrence remains unstable, it is not wholly identifiable. 

not fully circumscribe the occurrence or eliminate indeterminacy (if it did, the occurrence would be pinpointed). It may therefore be more problematic for a relative clause to be termed determinative in this case, since it does not fully determine (sense 2: elimination of indeterminacy) the occurrence.

A is as follows: since the clear-cut distinction between determinative and appositive clauses whose antecedent is determined with THE is founded on the relative clause being a condition for the pinpointing operation, is it possible to apply the same criterion regarding the link between extraction and qualification via a relative clause? In other words, is it possible to isolate cases when the relative clause conveys the condition for the operation of extraction marked by A?

We have analyzed examples in context ${ }^{2}$ and tried to specify, first, in which cases the relative clause is necessary for the type of determination conveyed by A. We then observed examples in which the qualification in the relative clause may not be relevant to A determination.

The purpose here is not to come up with yet another set of labels for the classification of relative clauses, but rather to focus on the relation between determination and qualification.

\section{The relative clause is necessary for determination with A}

In this first part, we shall analyze the cases for which the relative clause is involved in the construction of the occurrence itself, in relation to the delimitation of the notion inherent in the operation of extraction, marked with the indefinite article A.

\subsection{Construction of discontinuity with compact nouns}

19 In the framework of the theory of enunciative and predicative operations, so-called uncountable abstract nouns, such as "thickness" or "possession," are said to function as compact terms : the notions they refer back to are unsecable properties, referred to as nominalized predicates, or "prédicats nominalisés", ${ }^{3}$ which can only be apprehended through a medium or a relation. The notion of THICKNESS for instance is apprehended via an entity (object, person, or situation) through which the property "be thick" is made manifest, and the notion of POSSESSION through a relation between possessor and possessed. In the case of compact nouns, therefore, there is no template for the construction of an occurrence of the notion, since it depends on an external medium (thickness) or on external entities that are connected in the relation (possession). Compact nouns do not usually appear with the determiner A, and are only compatible with the indefinite article in certain conditions involving differential properties, as shown by Ronald Flintham (1999: 24):

The differential properties that allow for quantifiabilization and fragmentation may be conveyed by prepositional phrases [...] but also by other forms such as adjectives and 'determinative' relative clauses.

(4) Out of this mixture of tones-lardy flesh, rosy flesh, sallow flesh-his small eyes peered with a cheerfulness that was exaggerated at times, out of proportion to 
its object, as if Trick saw through the ordinary to another dimension invisible to his listeners. (Joyce Carol Oates, Wonderland, 1971)

(5) As a boy, he was exceptionally gentle; in adolescence, he assumed a roughness which I felt contradicted his nature. He's still rough, argumentative, sarcastic, but now he mocks the roughness and regards it as a comic scurf he can remove at will. Deep down - whatever this means - is the gentle boy he was at five and six; very lovable. (Richard Stern, The Illegibility of This World: A Story, 1992)

The nouns "roughness" and "cheerfulness", as nominalizations of adjectives, are typically compact nouns. In the case of these examples, removal of the relative clause would not allow for determination with A:

$\left(4^{\prime}\right)$ *His small eyes peered with a cheerfulness

$\left(5^{\prime}\right)$ *In adolescence, he assumed a roughness

Here it is important to note that the association of the properties "cheerful" and "rough" with a medium conveying those properties ("his eyes", "he") isn't sufficient for determination with A. Further qualification is needed, and it is to be found in the relative clauses.

In examples (4) and (5), the fragmentation operated on the notions of CHEERFULNESS or ROUGHNESS is linked to the predication conveyed in the relative clause, which constitutes a distinguishing property that isolates an occurrence of the notion. What are the specific features of these differential properties?

In example (4), the properties conveyed in the relative clause ("exaggerated", "out of proportion") are qualifications of degree: a certain degree of cheerfulness is referred to regarding his eyes. Another feature of the differential properties is that they are restricted in time: "at times" indicates that a distinction is operated on the class of instants: the notion (CHEERFULNESS) is brought into existence via the medium ("his small eyes") only in a subclass of situations ("at times"). Here the occurrence determined with $\mathrm{A}$ is therefore subjected to a double delimitation affecting both degree and existence in time. What's more, both degree and time constraints are constructed as unusual: deviation from the norm is at work in the category of degree ("exaggerated", "out of proportion") and in the category of time ("at times" = not often). This double exceptionality (in terms of degree and time constraints) gives the conditions for the differential delimitation of the occurrence of the notion and extraction with $\mathrm{A}$.

24 In 5 the fragmentation of the notion of ROUGHNESS is also restricted in time ("in adolescence" as opposed to "as a boy"), and the degree of roughness is also considered out of proportion, not as an absolute, but in relation to what is expected of the person in question ("contradicted his nature"). As regards the choice of the relative pronoun WHICH in 5, it can be noted that the subjective endorsement of the qualification in degree is explicitly mentioned in the embedded clause "I felt," in this case of relative concatenation. ${ }^{4}$

(6) I expected them to start flexing their muscles in a wrecking, ransacking assault on the ship. I did not expect anything like what happened. The three of them moved through the ship at a speed that I can hardly describe. (BNC: G3G Douglas Hill, The Fraxilly Fracas, 1989)

In (6), as in (4) and (5), the relative clause which follows the antecedent "speed" refers to a deviation from what is expected, to an exceptional degree of speed. Interestingly, we only found one example in the BNC of "at a speed" without any pre- or postmodifications: 
(7) To see where a particle is, you have to shine light on it. But Einstein had shown that you couldn't use a very small amount of light; you had to use at least one packet, or quantum. This packet of light would disturb the particle and cause it to move at a speed in some direction. The more accurately you wanted to measure the position of the particle, the greater the energy of the packet you would have to use and thus the more it would disturb the particle. (BNC: FYX Stephen Hawking, Black Holes and Baby Universes, 1994) when the interpretation of the antecedent is non-specific. Indeed, with specific, i.e. spatio-temporally situated occurrences, the gradual reduction of indeterminacy proceeds from the progressive identification or stabilization of the reference, and pinpointing follows extraction on the scale of determination. With non-specific occurrences, however, there is no gradual reduction of indeterminacy. Extraction in "A dog eats meat" refers to a representative occurrence of the class, whereas pinpointing in "The dog eats meat" refers to a prototypical occurrence. "A dog" and "the dog" are not in this case situated on a gradual scale, they are different ways of expressing genericity. Here "a dog" does not need to be identified or stabilized any further.

A case in point is that of the classifying use of A, as in "he is a doctor", with "a doctor" as subject complement of the subject "he". ${ }^{5}$ The specific occurrence "he" is assigned the notional property DOCTOR, by an operation of identification marked by BE, and that property is conveyed here by a qualitatively indifferent, representative occurrence, "a doctor", which functions as a locator (repère, in French).

(8) I had met Wyndham Farrar only once in my life before, though naturally I knew all about him, as did anyone who was connected with the theatre. And may I make it clear that I was connected only by marriage, I have no aspirations in that direction myself, though I have aspirations towards gloss, which can be mistaken for the same thing. Wyndham Farrar, in any case, was a name which one could not fail to recognize. He was a director, and everything he did, good or bad, achieved a certain distinction. (Margaret Drabble, The Garrick Year, 1965)

(9) I wonder if you are aware that in the Bible there are two words for time and that, generally speaking, they refer to two quite different ideas. The first word is used to describe ordinary time - past, present and future. The word used is chronos, from which comes our word 'chronology'. So dates like 1066 or Aunt Ethel's birthday all belong to chronos time. The other word, kairos, is a word that is used a great deal to describe God's breaking into our time and history to bring his salvation. (BNC: ABV George Carey, I Believe, 1991)

Without the relative clause, (8) and (9) would hardly be acceptable: "Wyndham Farrar was a name" would not make much sense, the notional property "name" being redundant to refer to the proper noun Wyndham Farrar. Similarly, in "the other word, 
kairos, is a word", the identification would be circular. The locator for Wyndham Farrar is not the notion NAME but the property expressed in the relative clause. "Name" only serves to support an external property which offers a fragmentation of the notion necessary for the occurrence to be used as a locator. The property conveyed in the relative clause in (9) is also necessary to stabilize the reference of the indefinite antecedent "a word" used as a locator. In (8), moreover, the property conveyed in the relative clause is particularly relevant in this context, as it marks a shift from the subjective perception of the narrator ("I had met [him]", "I knew him") to a subsequent, more objective, account of Wyndham Farrar's characteristics ("he was a director", "everything he did").

The classifying use of A can also be found in identifications with AS ("As a doctor...") and in appositions:

(10) My father tried to make out his face from where they were standing, but the man seemed to understand that they were talking about him and kept his head turned slightly away. The only feature that my father could make out was that of a rather abnormally long and narrow nose, a feature that seemed almost predatory in nature. (Dinah Mengestu, How to Read the Air, 2010)

The apposition in (10) also locates a specific occurrence (the man's nose) by providing it with a notional property (FEATURE), distinguishable only through the qualification to be found in the relative clause. This contributes to a further qualification of the feature in question ("long and narrow"), thus justifying its uniqueness ("the only feature that ...").

In those classifying uses of $\mathrm{A}$, the qualification conveyed in the relative clause provides the occurrence with a distinctive feature without which the occurrence would not be stable enough to serve as a locator in an operation of identification ${ }^{6}$.

Another case of a non-specific use of A is to be found in examples (11) and (12):

(11) - I think the mind is like a computer - you use a computer?

- I've got a laptop. I use it like a glorified typewriter. I have no idea how it does the tricks it does.

- OK. Your PC is a linear computer. It performs a lot of tasks one at a time at terrific speed. The brain is more like a parallel computer, in other words it's running lots of programs simultaneously. [...]

- You mean, you're trying to design a computer that thinks like a human being?

- In principle, that's the ultimate objective.

- And feels like a human being? A computer that has hangovers and falls in love and suffers bereavement?

A hangover is a kind of pain, and pain always has been a difficult nut to crack [...]. But I don't see any inherent impossibility in designing and programming a robot that could get into a symbiotic relationship with another robot and would exhibit symptoms of distress if the other robot were put out of commission. [...]

Or we may develop computers that are carbon-based, like biological organisms, instead of silicon-based ones. (David Lodge, Thinks..., 2001)

(12) ... expensive to repair, so it is not a major difficulty.

Look at the front door. From the point of view of security you do not want a door that is all glass, neither do you want a hollow plywood-type door that is easily kicked in. A solid door that has good, secure locks (preferably two - a Yale lock and a deadlock) and in which you can install a viewer, which will enable you to verify the identity of callers before you open the door, is an important feature. (BNC: BNL “The place where you live", One's Company. A Practical Guide to Enjoying your Independence, 1989) 
reference associated to the noun phrase in A is non-specific, inasmuch as its existence is not guaranteed in time and space but is apprehended prospectively on a hypothetical level, as shown by "trying to design", "the ultimate objective", "designing and programming", "may develop" in (11), and the repetition of "want" in (12). All these predicates are markers of an operation of location relative to an endpoint or telos, also called prospective validation (visée, in French). As in examples (8) to (10), the relative clause in (11) is necessary: it conveys the distinguishing property that specifies the element aimed at within the class of computers (not just any computer but a computer that...). The computers they are trying to design are different from existing computers ("carbon-based, like biological organisms, instead of silicon-based ones"), and the relative clause brings a qualitative determination to the notion that the antecedent refers to. It is the stabilizing power of that property which allows the indefinite antecedent to function as a locator.

In (12), the antecedent "a door" is the object of the verb "want" in the main clause, which is itself introduced by the prepositional phrase "From the point of view of security": both these characteristics very explicitly refer to prospective validation. In other words, what is "wanted" here is not just a door ("You do not want a door" is not interpretable in this context), but "a door that is secure", which means both "solid" and equipped with good, secure locks. Both these "features" are necessary for the occurrence "a door" to be stable enough referentially to serve as locator.

\subsection{Notional instability}

Another case in which the relative clause is constitutive of determination in A is that of nouns that are semantically vague or notionally unstable and require further qualification to be interpreted.

(13) She wanted to ask the troopers if they would go back to where they found her so they could do the journey all over again, this time slower, at a pace that matched the distance she felt she had traveled in her heart. (Dinaw Mengestu, How to Read the Air, 2010)

(14) This particular surveillance camera, I am almost certain, is manufactured by Vicon Industries, an overlooked leader in the field. Noting the deterioration and now wholesale abandonment of the noble notion of public education, I feel certain, and earlier cited statistics and the peculiar case of unreachable Indigo Children such as Dennis Junior here bear this out, we will soon be building prisons at a rate that will humble all the world, and so I have gathered in an Individual Retirement Account, a substantial portfolio of security industry stocks. (COCA: Steve Yates, "Report on Performance Art in One Province of the Empire Especially in Regard to Three Exhibitions Involving Swine," 2008)

In these examples, removal of the relative clause yields uninterpretable sequences:

$\left(13^{\prime}\right)$ *so they could do the journey all over again, this time slower, at a pace

$\left(14^{\prime}\right) *$ we will soon be building prisons at a rate

The type of measuring indicated by nouns such as "pace" and "rate" is insufficient per $s e$, and the specification provided in the relative clause is needed to stabilize reference sufficiently in order to posit the existence of an occurrence: the pace in (13), the rate in (14) can only be interpreted in their relation to the qualification in the relative clause.

(15) Wolverton stepped out onto a street. He could hear muffled sounds through his helmet. One of the city's inhabitants nearly stepped on him. He barely came up to its knee. Its head seemed quite small for its ungainly height. It took a long stride 
over him and quickly disappeared behind the tower. He wondered what he looked like to this alien, a tiny biped wearing a pressure suit. He was lucky it hadn't broken his spine under its huge foot. A thing that crawled in a curious gait on four legs, each with three joints, came from the other direction. Smaller limbs encircled its bumpy head, which was set on a thick neck over an hourglass torso. The head pivoted toward him, as if it were on a swivel. He got out of its way, his heart pounding and his breath coming in gasps. (COCA: Tim Sullivan, Star-Crossed, 2010) clause does not convey the conditions for extraction, but provides the occurrence with additional properties that are not used for pinpointing and stabilized identification of reference. In these cases, instability is reduced but not eliminated, and the process of stabilization isn't completed. The examples here will mainly include singular count nouns with specific reference in the utterance.

We will start by examining a short sample of these examples in order to show their common features regarding the relation of the relative clause to the determiner before fine-tuning the types of properties conveyed in the relative clause:

(16) The whole family of Samuel Josephs was there already with their lady-help, who sat on a camp-stool and kept order with a whistle that she wore tied round her neck, and a small cane with which she directed operations. (Katherine Mansfield, The Garden Party, 1922)

(19) On the table there stood a jar of sea-pinks, pressed so tightly together they looked more like a velvet pincushion, and a special shell which Kezia had given her grandma for a pin-tray, and another even more special which she had 
thought would make a very nice place for a watch to curl up in. (Katherine Mansfield, The Garden Party, 1922)

(25) Marguerite brought some fillet of beef on a blue-patterned dish which she set down in front of Madame Azaire. 'Should I bring some red wine?' she said.

'There's some from last night.' (Sebastian Faulks, Birdsong, 1993)

It is important to note that determination in $\mathrm{A}$ is the trace of the quantitative or existential delimitation of the occurrence and that the conditions for extraction are provided not in the relative clause, but in the main predication: the specific events associated to the existence of the occurrences are located in time and space via "there" and "kept order" in (16) and "brought" in (25), and existence of the occurrence is posited with "on the table there stood" (19). Predication of existence in specific situations anchors the occurrences of WHISTLE, SHELL and DISH, allowing for the existential delimitation marked by A. Unlike the examples in part one, suppression of the relative clause does not yield unacceptable utterances, even though it may change the thematic organization of the text:

(16') [...] their lady-help, who sat on a camp-stool and kept order with a whistle

(19') there stood a jar of sea-pinks [...] and a special shell

(25') Marguerite brought some fillet of beef on a blue-patterned dish

In these cases, qualitative determination in the relative clause is not constitutive of the existence of the occurrence subjected to the operation of extraction. In other terms, qualification via the relative clause does not participate in determination in the first sense of the term (operation conveyed via the determiner). Yet this external qualification, so to speak, provides the occurrence with properties that distinguish it from other occurrences of the class. In (16), for instance, the occurrence of WHISTLE is not strictly indistinguishable from other occurrences of the same class since it is provided with the property "worn tied round her neck". The occurrences of WHISTLE, SHELL and DISH, being qualified, are not strictly indistinguishable qualitatively from other occurrences of the same class, but the qualities in question are not used to identify and stabilize them completely, which would be the case if THE were used:

(16") kept order with the whistle that she wore tied round her neck,

$\left(19^{\prime \prime}\right)$ there stood a jar of sea-pinks [...] and the special shell which Kezia had given her grandma for a pin-tray,

$\left(25^{\prime \prime}\right)$ Marguerite brought some fillet of beef on the blue-patterned dish which she set down in front of Madame Azaire.

Here the relative clauses would be classified as determinative, since they provide the occurrence with the properties that are used to stabilize them, conditioning the pinpointing operation.

But as we have shown in the original examples determined with A, the relative clauses do not provide the condition for extraction. We will now examine the different types of properties conveyed in these cases by the relative clauses and their relation to the delimitation of the occurrences thus modified.

\subsection{Descriptive properties linked to background or origin}

(16) The whole family of Samuel Josephs was there already with their lady-help, who sat on a camp-stool and kept order with a whistle that she wore tied round her neck, and a small cane with which she directed operations. (Katherine Mansfield, The Garden Party, 1922) 
(17) They were there; they stepped out of the way of the hurrying people, and standing under a little iron stairway that led to the upper deck they began to say good-bye. (Katherine Mansfield, The Garden Party, 1922)

(18) On his first day in the city he found a quiet corner in Hampstead Heath. A guidebook for Americans that he had picked up in France had said that he would be afforded a wide, sweeping view of the city from there. (Dinaw Mengestu, How to Read the Air, 2010)

In these examples, the properties conveyed in the relative clauses have to do with a form of description concerning the location or origin of the occurrence ("round her neck"," to the upper deck", "in France"). There is no particular sign that the qualification is endorsed subjectively by the utterer, and the effect is that the property is treated as objective. This is to be linked to the use of the relative pronoun THAT, which is particularly compatible with constructing the qualification as an objective given.

\subsection{Causal relationship}

In the following examples, the relative clause is not the only qualifier, and the relation between the different forms of qualification is relevant to account for the role of the relative clause:

(19) On the table there stood a jar of sea-pinks, pressed so tightly together they looked more like a velvet pincushion, and a special shell which Kezia had given her grandma for a pin-tray, and another even more special which she had thought would make a very nice place for a watch to curl up in. (Katherine Mansfield, The Garden Party, 1922)

(20) She must have been stunningly beautiful in her youth, and still has a lovely face [...] but her figure is too matronly by today's exacting standards. She was wearing a lovely billowing silk dress which flattered her ample form. They certainly make a striking couple. She addresses him as 'Messenger', which has a curious, ambivalent effect. (David Lodge, Thinks..., 2001)

(21) And there's a supermarket and restaurants and sports halls - and an artificial lake for sailing and windsurfing that isn't quite big enough. (David Lodge, Thinks..., 2001)

(22) 'You're not suggesting I copied your character, are you?' she said. 'I thought perhaps you reproduced some details from my book without being aware of it,' I said. 'Oh no,' she said, shaking her head emphatically, 'that's impossible. I told you - I started my novel before I read yours.' 'Perhaps somebody else told you about it? Perhaps you read a review?' I said, trying desperately to find a face-saving explanation which we could both agree on, even if I didn't believe it. 'No,' she said flatly, 'I'd remember it.' 'Well then,' I said, throwing up my hands, 'I don't know what to say. I'm totally at a loss.' (David Lodge, Thinks..., 2001)

In these examples there is a causal relationship between two forms of qualification within the noun phrase. In (19), there is a causal relation to be seen between the relative clause and the adjective "special": it is because the shell is special that Kezia gave it to her grandmother. Similarly, in (20), the lovely and billowing qualities of the dress are the cause for its flattering her ample form. In (21), the property in the relative clause ("not big enough") is to be interpreted through the other postmodification ("for sailing and windsurfing"). And in (22), the property conveyed in the relative clause (agreement) makes the face-saving character of the explanation explicit.

51 The explanatory value of the qualification conveyed in the relative clause may also be found outside the noun phrase: 
(23) It's a round three-storey building with a domed roof that has a shallow indentation across the middle, very like an observatory except that there's no opening for a telescope. (David Lodge, Thinks..., 2001)

In (23), the qualifications expressed by "domed" and "shallow indentation" are complementary and justify the comparison with "an observatory", the locator introduced by "like": the roof's shape makes it look like an observatory.

(24) He sometimes went camping for a few days when things got bad at home. On one of these trips he saw a large piece of land that the government was selling and decided to buy it. The property was heavily wooded, had a small pond surrounded by birch trees, and a good sturdy building. The building needed some work, but Wharton thought that such a project would bring them all together. (T. Wolff, "Poaching", In the Garden of the North American Martyrs, 1981) the qualification conveyed in the relative clause is to be linked to the predication that immediately follows: it is because this piece of land is for sale that he can buy it.

this section the relative clause is in a causal or explanatory relationship with another element within or outside the noun phrase.

This is one of the traditional functions associated with appositive relative clauses. In French grammatical terminology, the term explicative is sometimes used as a synonym for appositive. L. Danon-Boileau and M. de Cola (1989: 135) also use the term concerning adjectival qualification in the case of adjectives associated with THIS and THAT in English:

Their [these adjectives'] function is rather to highlight one of the object's properties in order to justify the link with the predicate. [...] The qualities in question are not meant to distinguish contrastively or limit the noun's definition but to justify or explain the validation of the subject/predicate link.

\subsection{Plot advancing or continuative function}

(25) Marguerite brought some fillet of beef on a blue-patterned dish which she set down in front of Madame Azaire. 'Should I bring some red wine?' she said. 'There's some from last night.' (Sebastian Faulks, Birdsong, 1993)

(26) 'And genetic whatsitsnames?' Helen enquires, turning to Kenji.

The young man, whose English is not as good as Carl's, sweats and stammers through an explanation which Ralph tactfully summarizes for Helen's benefit: genetic algorithms are computer programs designed to replicate themselves like biological life forms. 'The programs are all set a problem to solve and the ones that do best are allowed to reproduce themselves for the next test. In other words, they pair off and have sex together' - so Ralph puts it, to the amusement of the students. (David Lodge, Thinks..., 2001)

Here, as in all examples in part 2, the conditions for the extraction marked by A are to be found not in the relative clauses, but in the main clauses (M. brought/The young man stammers through...). These predicates refer to events situated in time and space. However, the predications in the relative clauses (she set down/Ralph summarizes) create different, subsequent events involving the referents of the antecedents. This is also one of the possible features of traditional, detached appositive relative clauses, sometimes called plot-advancing or continuative.Reference is made to two separate states of affairs organized in an interpropositional chain of events (Mélis 10).

"Continuative ARCs: a specific kind of ARC which enables, by the depiction of an extra-linguistic event subsequent to that in the main clause, a forward movement 
within narrative time. [...] The ARC supports the trajectory of the narrative. The events are shown in a sequence and a causal link may be inferred. (Loock 2010: 96, 139)

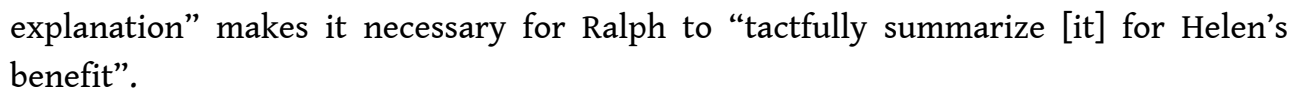
explanation" makes it necessary for Ralph to "tactfully summarize [it] for Helen's benefit". explanatory relationship to be found in section 2.2: "sweats and stammers through an

\section{Conclusion of part 2}

A hypothesis concerning the difference between the role of the relative clause when associated to extraction or pinpointing may now be formulated, in the case of specific reference.

- Pinpointing: the definite article as trace of a pinpointing operation indicates explicitly that the occurrence is maximally stabilized, in other words that indeterminacy is totally eliminated. In this case, qualification with an undetached relative clause is interpreted by default as the distinctive property that justifies the pinpointing operation. There is no dissociation here between determination 1 (operation conveyed by the determiner) and determination 2 (reduction of indeterminacy), and the relative clause is typically determinative. But if the pinpointing operation is justified elsewhere in the context or situation, then qualification of the occurrence via a relative clause will be explicitly detached (via a pause or a comma), and the relative clause typically appositive.

- Extraction: the quantitative/existential justification of determination 1 (operation of extraction conveyed through $\mathrm{A}$ ) is to be found not within but outside the noun phrase, via the predication in the main clause, and the qualification conveyed in the relative clause reduces indeterminacy (determination 2) but does not eliminate it. The occurrence remains unstable. Since the relative clause is not constitutive of determination 1 , there is no need for it to be explicitly detached, and the types of qualification conveyed are similar to those found in typical, detached appositive clauses (descriptive, causal/explanatory, plotadvancing).

\section{Conclusion}

In part 1 we observed cases for which the relative clause conveys the conditions for the extraction marked by determiner A. This concerns the passage from an unsecable, indivisible notion to an occurrence of said notion, as is the case when the noun is compact, or when a non-specific occurrence is used as an exemplar for the class. Here, the relative clause justifies determination 1 (operation conveyed by the determiner), and qualification as constitutive of determination 1 provides the notion with a form of delimitation that allows for the construction of an occurrence. In part 2, when the noun is discrete (countable) and the reference of the noun phrase specific, it is the existential anchoring of the occurrence that provides the delimitation of the occurrence, and this is justified outside the noun phrase. The relative clause 
participates in determination 2 (gradual reduction of indeterminacy). Qualification as reduction of indeterminacy is justified in similar ways as typically appositive relative clauses.

The "problematic", "unclassifiable" nature of undetached relative clauses in A is related to the interaction between the operation of determination and the qualification conveyed in the relative clause. This interaction is all the more complex in the case of A as the indefinite article is a marker that constitutes an intermediate, liminal stage in determination between the total instability of the notion (as conveyed via zero determination), and the total stability of the pinpointed occurrence (as conveyed through THE).

\section{BIBLIOGRAPHY}

BNC, see Davies 2004-.

COCA, see Davies 2008-.

Cotte, Pierre. "Les propositions relatives et l'énonciation" Cycnos 17, nº spécial (2000): 47-57. http://revel.unice.fr/cycnos/index.html?id=1697

Culioli, Antoine. Pour une linguistique de l'énonciation. Opérations et représentations. Tome 1. Paris: Ophrys, 1990.

Danon-Boileau, Laurent and Martine de Cola. "This, that et les adjectifs: construction de la référence." Cahiers de Recherche en Grammaire Anglaise. Tome 4. Paris : Ophrys (1989): 129-144.

Davies, Mark. BYU-BNC (Based on the British National Corpus from Oxford UP), 2004-. Available online at https://www.english-corpora.org/bnc/

Davies, Mark. The Corpus of Contemporary American English: 520 million words, 1990-present, 2008-. Available online at https://www.english-corpora.org/coca/

Flintham, Ronald. "Invariant et variation: les relatifs WHICH et THAT." Cycnos 15, nº spécial (1998): 157-70.

Flintham, Ronald. "La construction d'une occurrence individuée de notion nominale compacte en anglais sous la forme <A N (compact) WHICH/THAT>.” Cycnos 16.2 (1999): 21-37. http:// revel.unice.fr/cycnos/index.html?id=47

Fuchs, Catherine and Judith Milner. A propos des relatives. Étude empirique des faits français, anglais et allemands, et tentative d'interprétation. Paris: SELAF, 1979.

Gilbert, Eric. "Quelques remarques sur AS et la construction des valeurs référentielles." La référence 1, Statut et processus, Travaux du Cerlico 11, PUR (1998): 103-26.

Khalifa, Jean-Charles. La syntaxe anglaise aux concours. Théorie et pratique de l'énoncé complexe. Paris: Armand Colin, 2004.

Kleiber, Georges. "Remarques sur l'opposition 'relative restrictive/relative appositive' et l'article indéfini UN spécifique.” Travaux de Linguistique et de Littérature XXII.2 (1984): 179-91. 
Kleiber, Georges. "Relatives restrictives/relatives appositives: dépassement(s) autorisé(s)." Langages 88 (1987): 41-63. DOI: 10.3406/lgge.1987.2065

Loock, Rudy. Appositive Relative Clauses in English: Discourse Functions and Competing Structures. Amsterdam: John Benjamins, 2010.

Loock, Rudy. "Pour (enfin ?) en finir avec les deux types de relatives. La linguistique face aux limites de la catégorisation." Cercles 29 (2013): 21-45. http://www.cercles.com/n29/loock.pdf

Malan, Naomi. La proposition relative en anglais contemporain : une approche pragmatique. Paris: Ophrys, 1999.

Mélis, Gérard. “Relatives et types de qualification. Cycnos 17, nº spécial (2000): 1-20. http:// revel.unice.fr/cycnos/index.html?id=1693

Rivière, Claude and Nicole Rivière. "Sur l'opposition relative restrictive/relative appositive." Cycnos 17, n spécial (2000): 21-7.

\section{NOTES}

1. Translations of original quotations in French are ours.

2. The examples are taken from the BYU British National Corpus (Davies 2004-), hereafter referred to as BNC, the Corpus of Contemporary American English (Davies 2008-), hereafter referred to as COCA, and personal readings.

3. These are different from classic "mass nouns", called "dense" in the theory of enunciative operations, which are compatible with fragmentation involving measurable quantities. With compact nouns, quantifiers tend to involve the construction of degree rather than a measure of quantity

4. On the choice of the relative pronoun and its link to subjective endorsement, which is not the focus of this paper, see Flintham (1998) and Khalifa (2004: 203).

5. For a detailed analysis of the operation of identification relative to a notion, see Gilbert (1998).

6. In these examples, semantic vagueness is another factor for the necessity of the relative clause. This will be further explored in 1.3 .

7. See above, note 5 .

\section{ABSTRACTS}

The purpose of this paper is to observe the properties of undetached relative clauses qualifying nouns determined with the indefinite article A in the framework of the theory of enunciative operations. In this framework, determination is seen as a process through which indeterminacy is eliminated and occurrences are stabilised. We have observed the interaction of indefinite determination with the qualification expressed in the relative clause to sort out when the relative clause gives the conditions for determination in A and when its role is to qualify an occurrence whose conditions of existence are to be found elsewhere in the utterance. This contributes to explaining why undetached relative clauses with an indefinite antecedent are 
problematic vis-à-vis the classical distinction between determinative and appositive relative clauses.

Le but de cet article est d'observer les propriétés des propositions relatives non détachées dont l'antécédent est déterminé par l'article indéfini A dans le cadre de la théorie des opérations énonciatives. Dans ce cadre, la détermination est envisagée comme un processus d'élimination d'indétermination et de stabilisation des occurrences. Nous avons observé l'interaction de la détermination indéfinie et de la qualification exprimée dans la proposition relative afin de dégager les cas dans lesquels la proposition relative véhicule les conditions de la détermination en A de ceux dans lesquels elle qualifie une occurrence dont les conditions d'existence sont posées ailleurs dans l'énoncé. Ceci nous a permis de montrer en quoi les propositions relatives non détachées dont l'antécédent est déterminé par A posent problème au regard de la distinction classique entre propositions relatives déterminatives et appositives.

INDEX

Mots-clés: proposition relative, détermination, indétermination, article indéfini, théorie des opérations énonciatives, déterminative, appositive, stabilisation, notion, occurrence, extraction, fléchage

Keywords: relative clause, determination, indeterminacy, indefinite article, theory of enunciative operations, determinative, appositive, stabilization, notion, occurrence, extraction, pinpointing

\section{AUTHORS}

\section{STÉPHANE GRESSET}

Université Paris Diderot. Clillac-Arp, EA 3967. Contact: stephane.gresset [at] univ-paris-diderot.fr

\section{CATHERINE MAZODIER}

Université Paris Diderot. Clillac-Arp, EA 3967. Contact: catherine.mazodier [at] univ-parisdiderot.fr 